\title{
Emotional and neurobehavioural status in chronic pain patients
}

\author{
He Shuchang MD PhD ${ }^{1}$, He Mingwei $\mathrm{PhD}^{2}$, Jia Hongxiao $\mathrm{PhD}^{3}$, Wu Si PhD${ }^{1}$, Yang Xing $\mathrm{PhD}^{1}$, \\ Daniel Antonius $\mathrm{PhD}^{4}$, Mark GA Opler $\mathrm{PhD} \mathrm{MPH}^{4}$
}

H Shuchang, H Mingwei, J Hongxiao, et al. Emotional and neurobehavioural status in chronic pain patients. Pain Res Manage $2011 ; 16(1): 41-43$.

OBJECTIVE: To investigate the emotional and neurobehavioural status of patients suffering from chronic pain.

METHODS: Fifteen male patients with chronic lower back pain and 15 healthy control subjects were studied for approximately six months. Pain was measured using a visual analogue scale. The WHO Neurobehavioral Core Test Battery (NCTB) was used to assess neurobehavioural effects of environmental and occupational exposures.

RESULTS: Visual analogue scale results demonstrated a modest range of reported pain (mean $[ \pm S D] 62.0 \pm 10.8$ ) in chronic pain patients, whereas control subjects reported no measurable pain. With the NCTB, it was found that scores of negative mood state, including anger-hostility, depressiondejection, fatigue-inertia and tension-anxiety in pain patients were significantly higher than scores in the control subjects. By contrast, scores of positive mood state (vigour-activity) in chronic pain patients were lower than those in the control group. The NCTB scores of the Santa Ana Dexterity and Pursuit Aiming II tests in chronic lower back pain patients were lower than those of the control group. Scores for other NCTB subtests, including the Digit Span, Benton Visual Retention and Digit Symbol tests, were not significantly different compared with controls.

CONCLUSIONS: Chronic lower back pain patients had more negative mood and less positive mood than controls. These patients also demonstrated neuromotor deficits in coordination and reaction time. Further studies are required to examine possible neurological mechanisms and research potential intervention strategies for patients suffering from chronic pain.

Key Words: Chronic pain; Mood state; NCTB; Neurobehavioural

\section{L'état affectif et neurocomportemental des patients ayant des douleurs chroniques}

OBJECTIF : Examiner l'état affectif et neurocomportemental des patients ayant des douleurs chroniques.

MÉTHODOLOGIE : Les chercheurs ont étudié 15 patients de sexe masculin ayant des douleurs lombaires chroniques et 15 sujets témoins en santé pendant environ six mois. Ils ont mesuré la douleur au moyen d'une échelle analogique visuelle et évalué les effets neurocomportementaux de l'exposition environnementale et professionnelle à l'aide de la batterie des principaux tests neurocomportementaux (NCTB) de l'OMS.

RÉSULTATS : Les résultats de l'échelle analogique visuelle ont démontré une modeste plage de douleur déclarée (moyenne [ \pm ÉT] de $62,0 \pm 10,8$ ) chez les patients ayant des douleurs chroniques, tandis que les sujets témoins ne déclaraient aucune douleur mesurable. Au moyen de la NCTB, les chercheurs ont découvert que les indices d'humeur négative, y compris la colère et l'hostilité, la dépression et le cafard, la fatigue et l'inertie et la tension et l'anxiété, étaient considérablement plus élevés chez les patients ayant des douleurs que chez les sujets témoins. Par contre, les indices de bonne humeur (vigueur et activité) des patients ayant des douleurs chroniques étaient inférieurs à ceux des sujets témoins. Les indices de la NCTB à l'égard des tests de dextérité et de motricité II de Santa Ana obtenus par les patients ayant des douleurs lombaires chroniques étaient inférieurs à ceux des sujets témoins. Les indices des autres sous-tests de la NCTB, y compris les tests de mémoire des chiffres, de rétention visuelle de Benton et des chiffres-symboles, ne donnaient pas de résultats significativement différents de ceux des sujets témoins.

CONCLUSIONS : Les patients ayant des douleurs lombaires chroniques étaient davantage d'humeur négative et moins d'humeur positive que les sujets témoins. Ces patients démontraient également des déficits neuromoteurs de coordination et de temps de réaction. D'autres études s'imposent pour examiner les mécanismes neurologiques et documenter les stratégies d'intervention potentielles auprès des patients ayant des douleurs chroniques.

chronic pain have been shown to differ according to demographic factors such as ethnicity (6). Pain is an understudied problem in certain highly vulnerable subpopulations including frail elderly patients, especially those with cognitive impairment, delirium or dementia (7). Compared with other negative emotions, anger may have a reciprocal relationship with chronic pain severity by increasing muscle tension near the site of injury, ie, through symptom-specific reactivity (8).

Anxiety has a direct effect on chronic pain patients' perception of their disability (2). There is a strong relationship among negative emotions, pain and functioning, particularly because pain interference affects depression (2). Chronic pain is characterized by multiple comorbidities and under-reporting of symptoms; as many as $45 \%$ to $80 \%$ of inpatients have pain that contributes to functional impairments. This makes pain evaluation very challenging. Multiple lines of evidence indicate that patients who present to chronic pain units frequently have personality features that make assessment and therapy difficult (9).

${ }^{1}$ Department of Psychology, Peking University; ${ }^{2}$ Pain Clinic of Xuanwu Hospital, Capital Medical University; ${ }^{3}$ Beijing Anding Hospital, Capital Medical University, Beijing, China; ${ }^{4}$ Department of Psychiatry, Institute for Social and Psychiatric Initiatives (InSPIRES), New York University School of Medicine, New York, New York, USA

Correspondence: Dr Mark GA Opler, Department of Psychiatry, Institute for Social and Psychiatric Initiatives (InSPIRES), New York University School of Medicine, New York, New York 10016, USA. Telephone 646-234-3607, fax 646-758-8169, e-mail mark.opler@nyumc.org 
TABLE 1

Profile of Mood State (POMS) scores of chronic pain patients and control subjects

\begin{tabular}{lcccc}
\hline Item & $\begin{array}{c}\text { Chronic pain } \\
\text { patients }(\mathbf{n}=\mathbf{1 5})\end{array}$ & $\begin{array}{c}\text { Control subjects } \\
(\mathbf{n}=\mathbf{1 5})\end{array}$ & $\boldsymbol{t}$ & $\mathbf{P}$ \\
\hline POMSA & $17.60 \pm 10.95$ & $7.80 \pm 3.99$ & 3.256 & 0.003 \\
POMSC & $7.80 \pm 6.07$ & $5.47 \pm 3.44$ & 1.295 & 0.206 \\
POMSD & $20.33 \pm 13.17$ & $6.27 \pm 4.43$ & 3.920 & 0.001 \\
POMSF & $11.27 \pm 7.13$ & $5.87 \pm 1.64$ & 2.860 & 0.008 \\
POMST & $12.07 \pm 8.44$ & $5.33 \pm 4.05$ & 2.786 & 0.009 \\
POMSV & $15.27 \pm 6.32$ & $21.70 \pm 6.53$ & -2.756 & 0.010
\end{tabular}

Data presented as mean \pm SD. Domains: A Anger-hostility; C Confusionbewilderment; D Depression-dejection; F Fatigue-inertia; T Tension-anxiety; $V$ Vigour-activity

Chronic pain has also been associated with behavioural and cognitive impairments (7). Neurobehavioural testing is commonly recognized as a sensitive and valid method for detecting early dysfunction of the nervous system in connection with low-level exposure to neurotoxic agents, noise, stress and other exposures $(10,11)$. One particular test battery, the WHO Neurobehavioral Core Test Battery (NCTB), is often used to examine the effects of various exposures $(12,13)$. The NCTB is organized into seven subtests. These NCTB subtests include Profile of Mood States (POMS), Simple Reaction Time, Digit Span (DSP), Santa Ana Dexterity (SAN), Digit Symbol (DSY), Benton Visual Retention (BVR) and Pursuit Aiming II (PA). The purpose of the present article was to study the mood state and neurobehavioural changes in chronic pain patients to advance our understanding of chronic pain and facilitate novel treatment in these patients.

\section{METHODS}

\section{Subjects}

Subjects were recruited at Xuanwu Hospital in Beijing, China. Cases were sought at the outpatient pain clinic. Fifteen subjects were screened for inclusion using a visual analogue scale for clinically relevant pain. Other criteria for inclusion were right-handedness, nonsmoking status, and age between 26 and 45 years. All chronic pain patients included in the present study suffered from lower back pain for at least six months. Fifteen healthy subjects meeting the inclusion criteria without reports of pain were selected as the control group and matched for sex, income, handedness and smoking status. The average pain duration in chronic pain patients in the present study was 3.6 years. Subjects in both groups had between 13 and 15 years of education, a mean age of 41 years, and annual incomes of between RMB3000 and RMB5000. Subjects experiencing other diseases necessitating drug treatment or those presenting with high levels of alcohol consumption ( $500 \mathrm{~mL}$ ethanol/week or more) were excluded from the study.

The WHO-recommended NCTB was used for all test subjects in the present study. It has been translated and validated for use with Chinese-speaking subjects (10). The NCTB consists of two parts. One part is the six-section POMS questionnaire, which includes domains of anger-hostility (POMSA), confusion-bewilderment (POMSC), depression-dejection (POMSD), fatigue-inertia (POMSF), tensionanxiety (POMST) and vigour-activity (POMSV). These scales may all reflect psychological states in patients caused by chronic pain. The other part of the NCTB consists of six subtests: the DSP, which measures attention and auditory memory; the SAN, which tests manual coordination and speed; the DSY, a measure of cognition and motor speed; the BVR, which reflects visual cognition, and memory, coordination and speed; and the PA, another test of manual coordination and speed. The DSP is divided into DSPF (forward) and DSPB (backward); the SAN includes SANP (preferred hand) and SANN (nonpreferred hand); and the PA includes PAC (correct) and PAE (errors).
TABLE 2

Scores of neurobehavioural tests of chronic pain patients and control subjects

\begin{tabular}{lcccc}
\hline Item & $\begin{array}{c}\text { Chronic pain } \\
\text { patients }(\mathbf{n}=15)\end{array}$ & $\begin{array}{c}\text { Control subjects } \\
(\mathbf{n}=15)\end{array}$ & $\boldsymbol{t}$ & $\mathbf{P}$ \\
\hline DSP & $19.47 \pm 4.16$ & $21.20 \pm 2.60$ & 1.37 & 0.182 \\
SANP & $58.87 \pm 13.71$ & $69.27 \pm 10.20$ & 2.36 & 0.026 \\
SANN & $62.33 \pm 14.89$ & $75.47 \pm 14.74$ & 2.43 & 0.022 \\
DSY & $18.13 \pm 10.33$ & $22.20 \pm 7.15$ & 1.25 & 0.220 \\
BVR & $7.07 \pm 1.10$ & $6.60 \pm 1.12$ & 1.15 & 0.260 \\
PA & $163.07 \pm 42.23$ & $209.3 \pm 48.08$ & 2.80 & 0.009 \\
\hline
\end{tabular}

Data presented as mean \pm SD. BVR Benton Visual Retention; DSP Digit Span; DSY Digit Symbol; PA Pursuit Aiming II; SANN Santa Ana Dexterity - nonpreferred hand; SANP Santa Ana Dexterity - preferred hand

\section{RESULTS}

The mean $( \pm S D)$ visual analogue scale score for chronic pain patients was $62.0 \pm 10.8$. The results of the POMS measurements for patients and control subjects are reported in Table 1. The POMSA, POMSD, POMSF and POMST scores in chronic pain patients were significantly higher than the corresponding scores in the control subjects $(\mathrm{P}<0.05)$. The POMSV score in chronic pain patients was significantly lower than that in the control subjects. By contrast, the POMSC score in chronic pain patients was not significantly different from that in the control subjects.

Results from neurobehavioural tests are reported in Table 2. SANP, SANN and PA scores in chronic pain patients were significantly lower than those of the control subjects. DSY, BVR and DSP of the chronic pain patients were similar to those in controls.

\section{DISCUSSION}

In clinical populations and research settings, most patients with chronic pain experience varying degrees of emotional distress (14). The most commonly reported forms of distress are feelings of anxiety and depression. Pain-induced depression has been shown to be a prognostic factor for long-term disability in patients with lower back pain (15). Anger, frustration and resentment are also reported, but these have received less attention in the literature (16). It is generally acknowledged that negative mood state modulates pain perception and may impact the effectiveness of pain management.

To our knowledge, no previous study has investigated the effects of chronic lower back pain on structured neurobehavioural measures across neuromotor and quantitatively defined ranges of emotional states. However, there are several studies that investigated the relationship between chronic pain and a negative mood state such as depression (15). As a stressor, chronic pain itself may induce negative mood states, which, in turn, affect biological and behavioural responses, which may provide feedback that will further negatively affect the patient's emotional responses. This might produce a vicious cycle with eventual disability and severe reductions in perceived quality of life as a consequence (17). It has been reported that serum cortisol levels are elevated or otherwise modulated in patients with chronic pain (18). This may be the result of stress-induced hypersecretion of corticotropin-releasing hormone, coupled with failure of negative feedback controls to limit the cortisol response (19). As a stressor, chronic pain and the related negative mood state both could induce cortical levels elevated in serum and salivary secretions $(20,21)$.

In our study, high scores in the POMSA, POMSD, POMSF and POMST domains were seen among chronic pain patients compared with control subjects. Depression has been reported to be associated with higher levels of self-reported pain and pain behaviour, feelings of helplessness and loss of control, and poor response to treatment $(22,23)$. Our neurobehavioural test results showed that pain patients had deficits in manual coordination and reaction speed, as shown in the results from the SANN, SANP and PA. 
Previously, investigators have demonstrated (24) that chronic lower back pain is associated with impaired performance on a complex emotional decision-making task, suggesting abnormal prefrontal processing. Abnormal brain chemistry (25) and thalamocortical atrophy (26) has also been discovered in these patients. Coupled with our own findings, this literature suggested that clinical treatment of chronic pain should integrate mental health modalities, including psychological and psychiatric consultation (9).

Interpretation of our results warrants some caution because they are correlational and do not permit causal assertions. Also, our sample size is relatively small, which limited our ability to explore group differences on pain and social/occupational functioning. To better understand the relationship between chronic pain, neurobehavioural state, and longterm social and occupational outcomes, we suggest that future studies

\section{REFERENCES}

1. Dunajcik L. Chronic nonmalignant pain. In: McCaffery M, Pasero C, eds. Pain: Clinical Manual, 2nd edn. St Louis: Mosby, 1999:467-521.

2. Tsang A, Von Korff M, Lee S, et al. Common chronic pain conditions in developed and developing countries: Gender and age differences and comorbidity with depression-anxiety disorders. J Pain 2008;9:883-91. (Erratum in 2009;10:553).

3. Tan G, Jensen MP, Thornby J, Sloan PA. Negative emotions, pain, and functioning. Psychol Serv 2008;5:26-35.

4. Zanocchi M, Maero M, Nicola E, et al. Chronic pain in a sample of nursing home residents: Prevalence, characteristics, influence on quality of life (QoL). Arch Gerontol Geriatr 2008;47:121-8.

5. Dersh J, Polatin PB, Gatchel RJ. Chronic pain and psychopathology: Research findings and theoretical considerations. Psychosom Med 2002;64:773-86.

6. Riley JL, Wade JB, Myers CD, Sheffield D, Papas RK, Price DD. Racial/ethnic differences in the experience of chronic pain. Pain 2002;100:291-8.

7. Frondini C, Lanfranchi G, Minardi M, Cucinotta D. Affective, behavior and cognitive disorders in the elderly with chronic musculoskeletal pain: The impact on an aging population. Arch Gerontol Geriatr 2007;44:167-71.

8. Burns JW. Arousal of negative emotions and symptom-specific reactivity in chronic low back pain patients. Emotion 2006;6:309-19.

9. Pridmore S, Oberoi G, Harris N. Psychiatry has much to offer for chronic pain. Aust N Z J Psychiatry 2001;35:145-9.

10. Zhou W, Liang Y, Christiani DC. Utility of the WHO neurobehavioral core test battery in Chinese workers a meta-analysis. Environ Res 2002;88:94-102.

11. Young T, Myers JE, Thompson ML. The nervous system effects of occupational exposure to manganese measured as respirable dust in a South African manganese smelter. Neurotoxicology 2005;26:993-1000

12. Anger WK, Liang YX, Nell V, et al. Lessons learned - 15 years of the WHO-NCTB: A review. Neurotoxicology 2000;21:837-46.

13. Cassitto MG, Camerino D, Imbriani M, Contardi T, Masera L, Gilioli R. Carbon disulfide and the central nervous system: build on the findings from our group and others via observational methods (eg, ecological approaches) that integrate quantitative psychometric and biological measures. Additionally, future studies that more specifically investigate the effects of pain on different cognitive functioning measures, as well as controls for mediating factors, will provide the field with valuable new knowledge that may help set the stage for the development of novel treatments for pain.

ACKNOWLEDGEMENTS: This work was supported by grants from the National Natural Science Foundation of China (No 30400135, No 30670708 and No 30870768) and a United States National Institutes of Health K01 Career Development Award (No 5K01MH080114-02, principal investigator: M Opler).

A 15-year neurobehavioral surveillance of an exposed population. Environ Res 1993;63:252-62.

14. Pincus T, Santos R, Morley S. Depressed cognitions in chronic pain patients are focused on health: Evidence from a sentence completion task. Pain 2007;130:84-92.

15. Pincus T, Vlaeyen JWS, Kendall NA, Von Korff MR, Kalauokalani DA, Reis S. Cognitive-behavioral therapy and psychosocial factors in low back pain: Directions for the future. Spine 2002;27:133-8.

16. Nicola A. Psychological approaches to chronic pain management: Part 1. J Clin Nurs 2006;15:290-300.

17. Truchon M. Determinants of chronic disability related to low-back pain: Towards an integrative model. Disabil Rehabil 2001;23:758-67.

18. Kimberly DE, Douglas B, Bruce N, Drummond PD. An exploratory study of changes in salivary cortisol, depression, and pain intensity after treatment for chronic pain. Pain Med 2008;9:752-8.

19. van Praag HM. Can stress cause depression? Prog Neuropsychopharmacol Biol Psychiatry 2004;28:891-907.

20. Cowen PJ. Cortisol, serotonin and depression: All stressed out? Br J Psychiatry 2002;180:99-100.

21. Atkinson JH Jr, Kremer EF, Risch SC, Dana R, Janowsky DS. Neuroendocrine responses in psychiatric and pain patients with major depression. Biol Psychiatry 1986;21:612-20.

22. Haythornthwaite JA, Menefee LA, Heinberg LJ, Clark MR. Pain coping strategies predict perceived control over pain. Pain 1998;77:33-9.

23. McDonald M. Assessment and management of cancer pain in the cognitively impaired elderly (CE). Geriatr Nurs 1999;20:249-53.

24. Apkarian AV, Sosa Y, Krauss BR, et al. Chronic pain patients are impaired on an emotional decisionmaking task. Pain 2004;108:129-36.

25. Grachev ID, Fredrickson BE, Apkarian AV. Abnormal brain chemistry in chronic back pain: An in vivo proton magnetic resonance spectroscopy study. Pain 2000;89:7-18.

26. Apkarian AV, Sosa Y, Sonty S, et al. Chronic back pain is associated with decreased prefrontal and thalamic gray matter density. J Neurosci 2004;46:10410-5. 


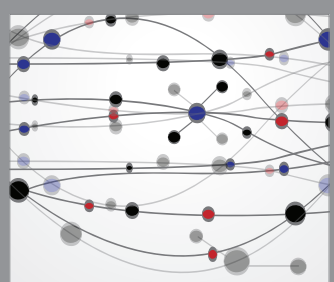

The Scientific World Journal
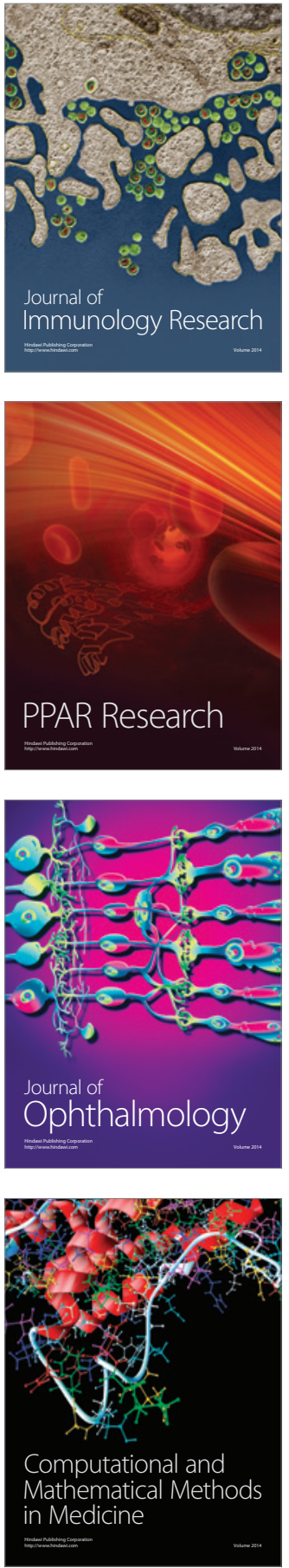

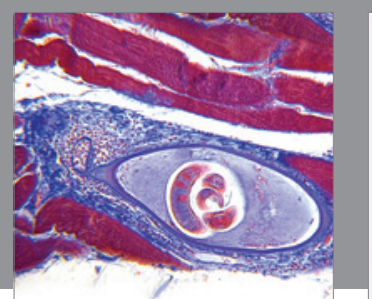

Gastroenterology Research and Practice

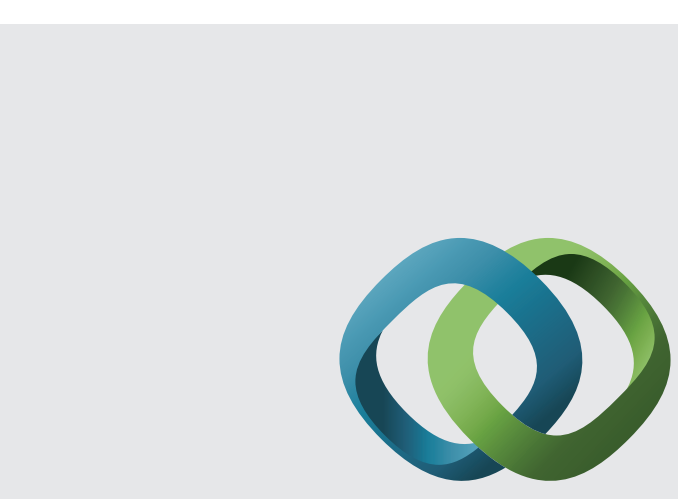

\section{Hindawi}

Submit your manuscripts at

http://www.hindawi.com
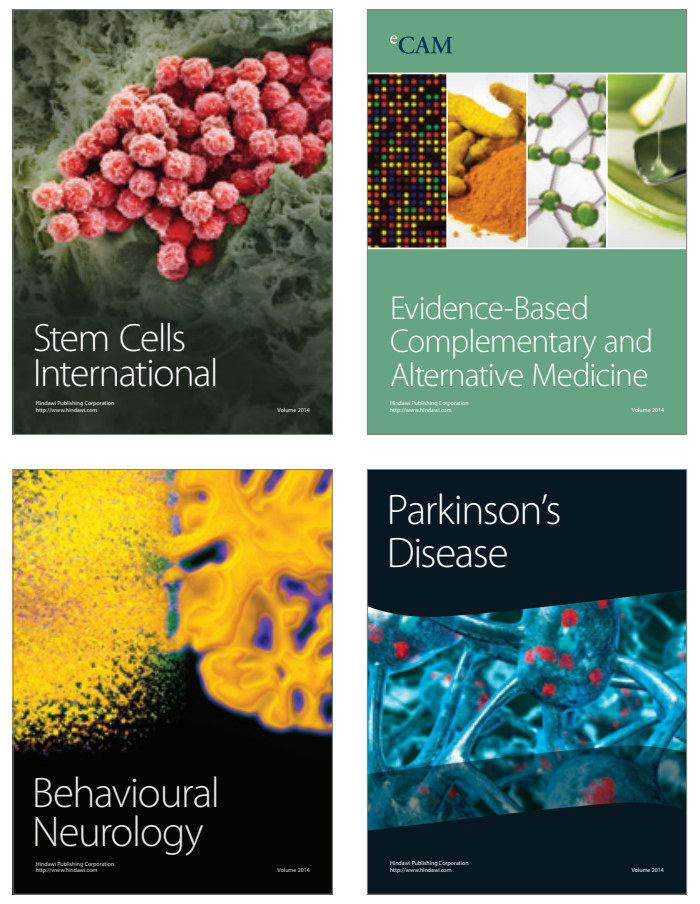
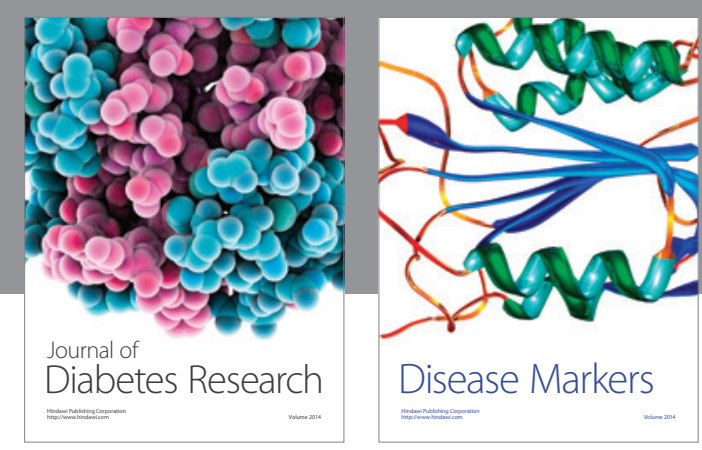

Disease Markers
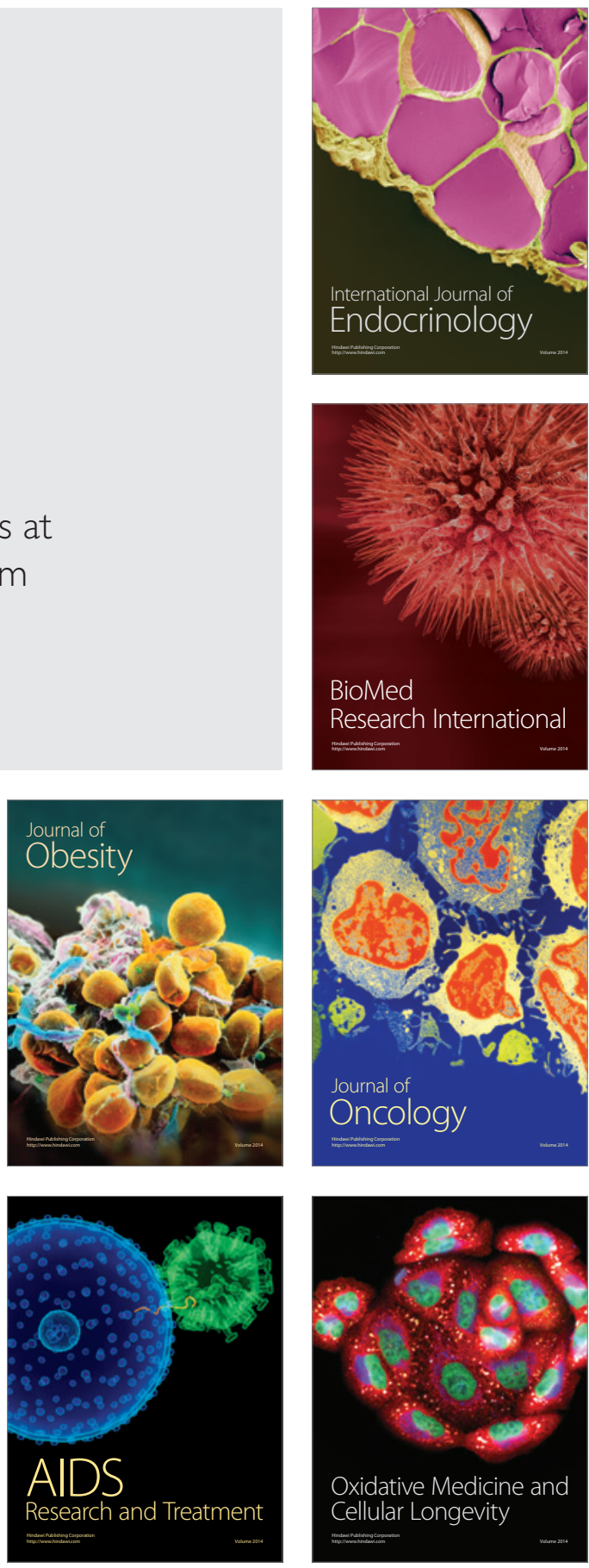